\title{
National electronic health records initiative remains muddled, auditors say
}

Published at www.cmaj.ca on Apr. 21

$\mathrm{S}$ ix provincial auditors joined with federal Auditor General Sheila Fraser yesterday to release a report depicting a dismal picture of Canada's efforts to build a national health "infostructure."

The report, which mixes modest praise with severe criticism, indicates that Canada Health Infoway will not meet its stated objective of having $50 \%$ of Canadians with electronic health records (EHRs) by the end of 2010, and offers a long list of unanswered questions related to taxpayers' multibilliondollar investment in electronic recordkeeping.

The report reviews concurrent performance audits of the development of EHRs in Alberta, British Columbia, Nova Scotia, Ontario, Prince Edward Island and Saskatchewan, as well as Fraser's performance audit of Canada Health Infoway, which is overseeing the pan-Canadian initiative to build EHR systems.

The remaining provinces and territories opted not to participate in the concurrent audit. They collectively received about $40 \%$ of the $\$ 1.229$ billion that Infoway dispensed through Mar. 31, 2009, led by Quebec (\$295 million), Newfoundland and Labrador (\$65 million) Manitoba (\$53 million), New Brunswick (\$38 million), Northwest Territories (\$12 million), Nunavut (\$7 million), and Yukon (\$2 million).

The report, Electronic Health Records in Canada: an overview of Federal and Provincial Audit Reports, April 2010 , indicates that development and implementation of EHRs across the country has occasionally been haphazard, with some provinces moving ahead without "comprehensive strategic plans" to guide development and adoption, and others sometimes proceeding without adequate oversight or regard to recognized project management methodolo-

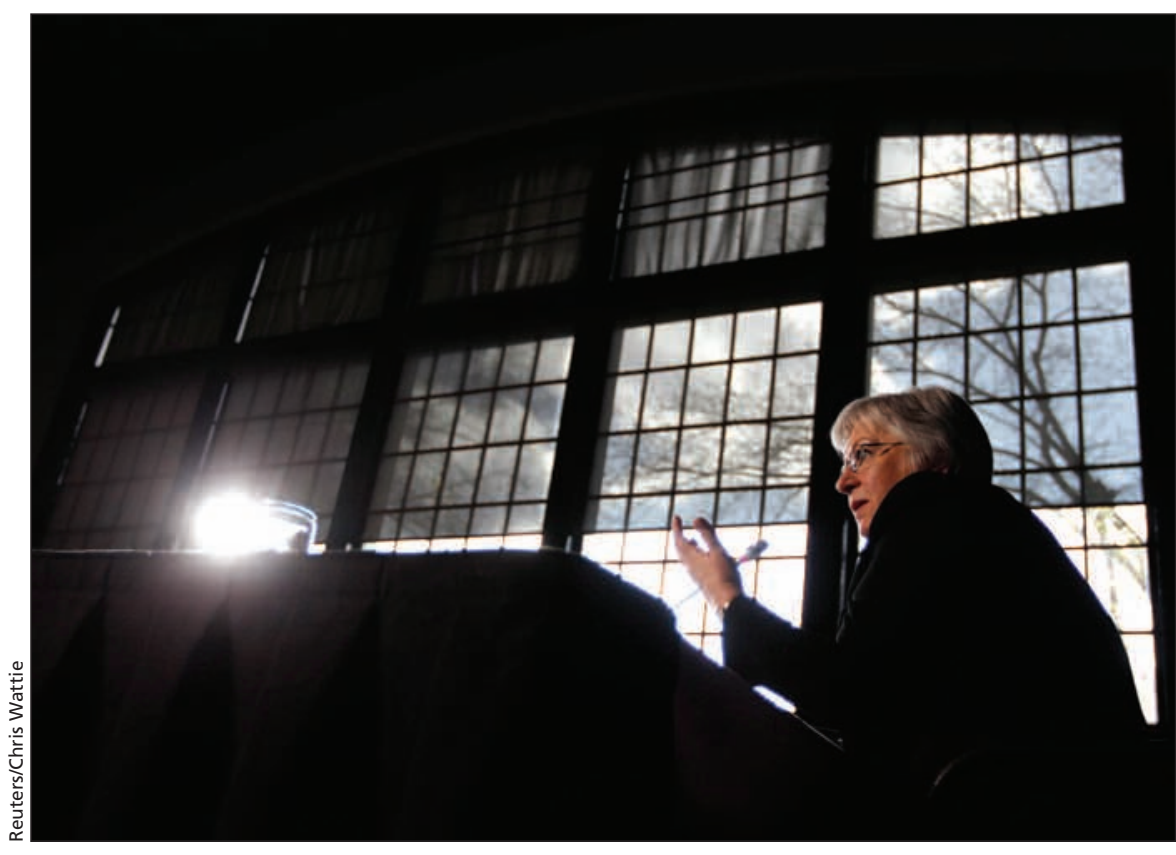

Canada's Auditor General Sheila Fraser speaks during a news conference following the release of her report in Ottawa on Apr. 20.

gies (www.oag-bvg.gc.ca/internet/docs /parl_oag_201004_07_e.pdf).

In broad terms, it notes that even the overall public investment in EHRs remains unquantifiable across Canada, as not all provinces have "consistently tracked their total costs. Therefore, the total costs to date of the EHR initiative are unknown."

The report also says that "some experts have estimated the total cost of implementing EHRs Canada-wide at over $\$ 10$ billion and the total annual benefits at $\$ 6$ billion."

Yet even those figures may be wildly underestimated. Canada Health Infoway Chief Technology Officer Dennis Giokas told a conference on EHRs in Montréal, Quebec, on Monday that the organization's investments will represent about $10 \%$ of the final costs for a national health records system. By that calculation, the total costs of a national system will easily surpass $\$ 20$ billion, or twice the figure referenced in the new audit report.

The uncertainty of financial projections within the concurrent audit is mirrored by the highly fragmented state of the ongoing effort to create a pan-Canadian EHR system.

A decade after the federal government committed to leading the effort, the auditors state that "Infoway, in collaboration with the provinces and territories, has accomplished much in the eight years since its creation but that, coordination is still severely lacking, particularly within some provinces."

"No province had plans for individual projects that adequately linked to strategic plans," the new report notes. "When there is no EHR strategic plan at the provincial level or when links between plans are weak, it is unclear when component systems will be developed or upgraded; it is also unclear which systems will need to be upgraded. Furthermore, there is a risk 
that the projects undertaken will not be consistent with the goals and priorities of the overall EHR initiative and that the needs of the users will not be met."

The report warns that provincial parochialism could kneecap a national system built on compatible technologies that create "interoperable" health information systems. "Provinces have reported that they intend to comply with standards, but it is too soon to have certainty about whether the systems in their jurisdictions will be compatible. In addition, it is not clear when existing systems will be upgraded, if necessary, to meet standards for compatibility."

The audit findings indicated that project management practices varied from province to province. In Saskatchewan, overall costs and timelines were not monitored. In Alberta, the business cases to justify the components of the EHR were not developed consistently. In Ontario, weak oversight of project expenditures was reported. In PEI, project management weaknesses were identified for the period 2005-2009 and monitoring and reporting of project costs continues to be a problem.

"Ministries of Health with inadequate project management processes are less able to properly manage costs, risks, and problems," the report warns. "As a result, projects may not meet the ministries' timelines or user expectations."

Complex EHR systems require clear leadership and direction from a central authority, and clear reporting of results, the auditors noted. But this has been lacking in many places, they state. "As a result the provincial ministries of health and the public are currently unable to assess whether the initiative is achieving its goals and objectives, on time and within budget. Additional information on progress and on the availability and use of EHRs is needed so the legislatures and Canadians can determine whether they have received value for the investments made thus far, and whether they will do so in the future."

The audit concludes by asking:

- whether the EHR system be finished on time, as defined by each jurisdiction and Infoway;

- whether EHRs really will save an estimated $\$ 6$ billion a year in health care costs;

- whether the systems being built are compatible;

- whether physicians will be able to benefit;

- whether patients will be able to benefit;

- whether privacy concerns will be met;

- whether funding will be provided;

- whether the actual costs will ever be communicated. - Paul Christopher Webster, Toronto, Ont.

DOI:10.1503/cmaj.109-3242 